\title{
Geomorfología natural del territorio municipal de Chía, Cundinamarca/Colombia
}

\author{
Natural geomorphology of the Chía municipal territory, \\ Cundinamarca/Colombia
}

Miguel A. Castiblanco S., Geógrafo, Universidad Nacional de Colombia, Maestrante en Geografía del Programa EPG convenio UPTC-IGAC, Colombia, macastiblancos@unal.edu.co

https://orcid.org/0000-0001-7960-2028

Resumen: El artículo se centra en la descripción y explicación de los aspectos geomorfológicos naturales para el municipio de Chía, localizado en la Cordillera Oriental colombiana. La caracterización a escala 1:25.000 se fundamenta en el enfoque conceptual "sistema morfogénico" y en revisión documental; la zonificación se elabora a partir de la interpretación de insumos, el análisis de variables, la aplicación de geotecnologías y el trabajo de campo. Los factores condicionantes han determinado la conformación de cinco ambientes morfogénicos: periglaciar heredado, estructural, coluvio-aluvial, fluvio-lacustre y fluvial, cada uno con geoformas específicas; en la morfodinámica sobresalen los procesos fluviales activos, con desbordes periódicos para los valles aluviales Bogotá y Frío. Al final, se muestra un panorama preliminar de la intervención humana sobre los relieves y modelados naturales, y se indica la relevancia de los resultados para los futuros estudios antropogeomorfológicos.

Palabras clave: Altiplano de Bogotá; Geoformas fluvio-lacustres; Inundaciones; Mapeo geomorfológico; Sistema morfogénico.

\begin{abstract}
The article focuses on the description and explanation of the natural geomorphological aspects for the Chia municipality, located in the Colombian Eastern Cordillera. The characterization at $1: 25.000$ scale is based on the conceptual approach "morphogenic systems" and the documentary review; the zoning is elaborated from the interpretation of inputs, the analysis of variables, the application of geotechnologies and the field work. The conditioning factors have determined the conformation of five morphogenic environments: inherited periglacial, structural, colluvio-alluvial, fluviolacustrine and fluvial, each one with specific landforms; in the morphodynamics the active fluvial processes stand out, with periodic overflows for the Bogotá and Frío alluvial valleys. At the end, a preliminary overview of human intervention on the natural reliefs and moldings is shown, and the relevance of the results for future anthropogeomorphological studies is indicated.
\end{abstract}

Keywords: Bogotá Altiplano; Fluvio-lacustrine landforms; Floods; Geomorphological mapping; Morphogenic system.

\section{Introducción}

La caracterización de la geomorfología natural es una fase investigativa inicial, que busca comprender los diferentes aspectos de los sistemas morfogénicos de los territorios, sin contemplar en principio y de manera deliberada la influencia humana. Nir (1983) y Rodrigues (2005) reconocen la importancia de discriminar y solventar esta etapa definida por los autores como "estado original" o de "pre-perturbación", cuyo interés es dar un acercamiento y establecer en lo posible las condiciones previas a las diversas intervenciones antrópicas. 
El propósito del trabajo es responder a las inquietudes: ¿cuáles son las geoformas naturales en Chía?, ¿cómo se distribuyen en el área municipal?, y ¿qué procesos morfogénicos y morfodinámicos naturales han actuado y actúan en su marco territorial? Así pues, los objetivos del presente documento se centran en describir y explicar tanto las geoformas como los procesos geomórficos del escenario municipal, aislando premeditadamente la influencia humana, pero al final, con la identificación preliminar de algunos sitios actuales modificados por el accionar antropogénico.

Las descripciones y explicaciones sobre el contexto geomorfológico regional y local se fundamentan en el concepto: sistema morfogénico adaptado y empleado para Colombia (Flórez, 2003; CAR, 2006; IDEAM, 2010), el cual conlleva al análisis de varios factores, que, en conjunto, determinan la configuración de los diferentes ambientes, relieves y modelados. Las salidas gráficas y cartográficas incluyen una categorización y espacialización de unidades clasificadas en función de la propuesta nacional del IDEAM (2010), con ajustes proporcionados por el reconocido Sistema ITC (Van Zuidam, 1985; Verstappen y Van Zuidam, 1991; Carvajal, 2012; Zinck, 2012; Robertson, Jaramillo y Castiblanco, 2013; IGAC, 2018).

Con los resultados se procura constituir un insumo inicial y esencial, que permita en una fase investigativa posterior confrontar y analizar las dinámicas geohistóricas de ocupación, uso y antropización. Asimismo, se busca presentar y consolidar una nueva alternativa para caracterizar las realidades geomorfológicas de los entes territoriales municipales en Colombia. Al final, y con base en los resultados, se incluye un primer panorama del accionar antrópico; con una reflexión sobre el factible aprovechamiento de la caracterización natural en los estudios geomorfológicos de corte antropogénico, así como su aplicación recomendada en las necesarias tareas de planificación, gestión ambiental y re-ordenamiento del territorio.

\section{Referente conceptual: el sistema morfogénico}

La geomorfología moderna fundada desde finales del siglo XIX (Church, 2010) se preocupa en la actualidad por cuatro grandes enfoques que reflejan en general el rumbo de sus estudios: la evolución geohistórica, las caracterizaciones, las interacciones proceso-forma (proceso-respuesta) y la sensibilidad o proyección ambiental (Slaymaker, 2009, como se citó en Huggett, 2017).

Respecto a las relaciones proceso-forma se destaca la concepción "sistema morfogénico", el cual es definido por Flórez (2003, p. 218) e IDEAM (2010, p. 21) (en referencia a Tricart, 1977 y Summerfield, 1994) como el "conjunto de procesos interdependientes que generan un modelado específico en un espacio determinado". De acuerdo con estos autores, el sistema morfogénico recalca en la preeminencia del enfoque proceso-forma: procesos entendidos como acciones de la dinámica externa (en menor medida la interna) que movilizan, transfieren y depositan materiales; y geoformas, concebidas como objetos superficiales terrestres, específicos y distintivos, internamente organizados, y resultantes de los agentes dinámicos formadores (Flórez, 2003; IDEAM, 2010). 
En ese sentido, para la identificación de un sistema morfogénico es primordial establecer geoformas y procesos causales, además de considerar la influencia de factores como la morfoestructura geológica, las formaciones superficiales, las pendientes del terreno, los aspectos bioclimáticos, y dependiendo del interés investigativo los diferentes aspectos humanos. El abordaje desde esta perspectiva permite instaurar así una estructura sistémica, jerárquica y de connotación multiescalar para las zonificaciones y explicaciones geomorfológicas, que facilita asimismo la diferenciación de los diversos ambientes, relieves y modelados en función de los agentes, procesos y sus características (Flórez, 2003; IDEAM, 2010).

Aunque de manera particular puede existir un énfasis solo en los factores naturales, los sistemas morfogénicos permiten incorporar las relaciones progresivas que se derivan de los objetos y las acciones sociales (ocupación, usos, antropización, etc.). En la actualidad, estas crecientes dinámicas toman relevancia como agentes generadores, modificadores o degradadores de geoformas, tal como se ha demostrado en los estudios realizados por Nir (1983), Rodrigues (2005), Szabó (2010), Goudie y Viles (2016), entre otros autores.

\section{2. Área de estudio y marco metodológico}

El territorio municipal de Chía es una unidad político-administrativa que pertenece al departamento de Cundinamarca en la República de Colombia. Hace parte a su vez de la Cordillera Oriental de los Andes colombianos y se sitúa en el sector central de la cuenca hidrográfica alta del río Bogotá (Figura 1).

Chía presenta una superficie aproximada de $80 \mathrm{~km}^{2}$, con elevaciones entre 2.540 y $3.230 \mathrm{~m}$ s. n. m. La zona central del territorio se emplaza sobre el Altiplano de Bogotá, con modelados relativamente planos en los que se ha concentrado la población urbana; hacia los flancos oriental y occidental sobresalen los relieves montañosos abruptos, con un poblamiento humano menor.

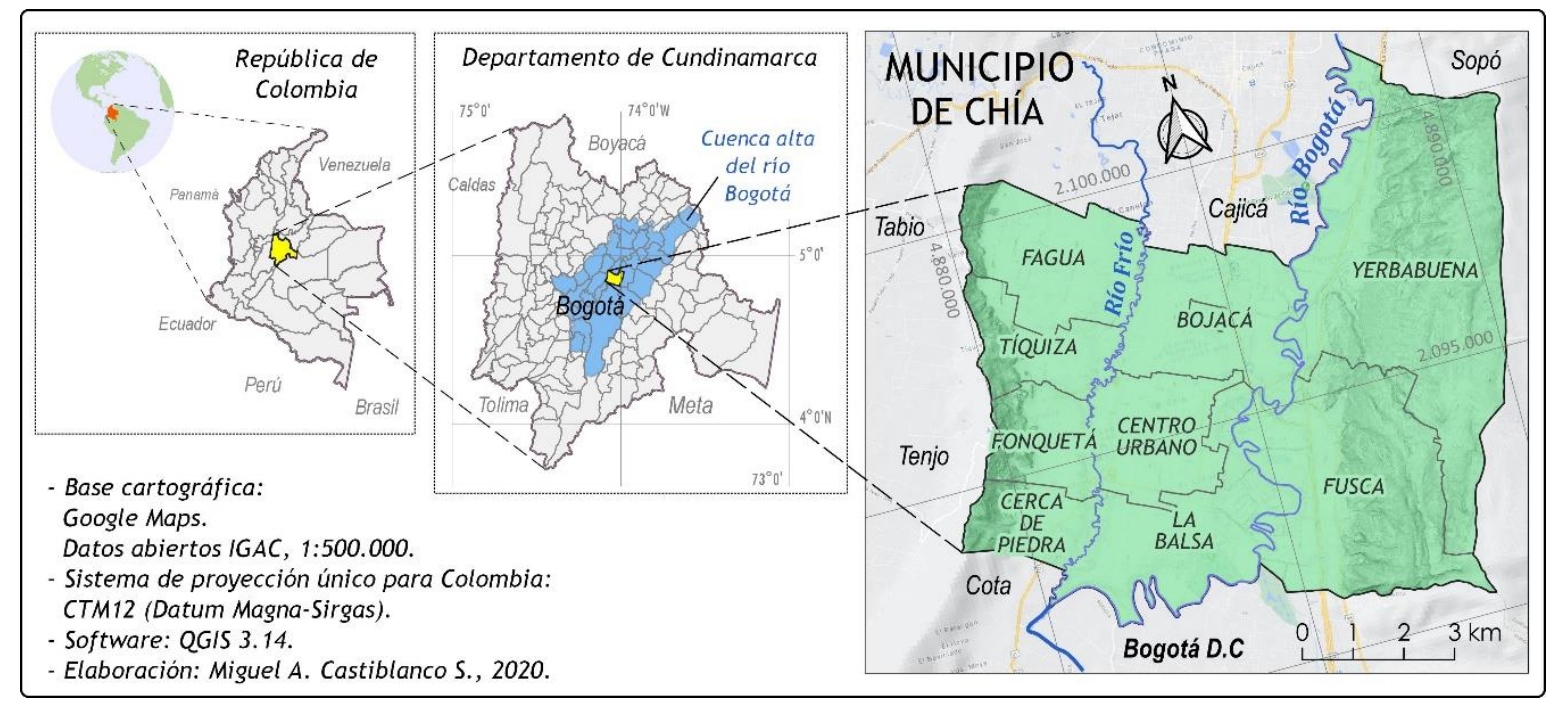

Figura 1: Localización del área de estudio

Fuente: elaboración propia. 


\section{Materiales y métodos}

La caracterización geomorfológica natural se realizó a partir de: a) la revisión documental de recursos bibliográficos, documentos teórico-metodológicos, memorias temáticas e informes técnicos; b) la fotointerpretación de insumos geohistóricos aerofotográficos, cartográficos y de imágenes (Tabla I); c) el uso de herramientas geotecnológicas y la aplicación de procedimientos de análisis espacial; y d) el trabajo de validación en campo.

Tabla I: Insumos usados en la fotointerpretación

\begin{tabular}{|c|c|c|c|c|}
\hline Tipo & Vuelo & Fotografía o plancha & Escala/Res. & Año \\
\hline \multirow{4}{*}{$\begin{array}{l}\text { Aerofotografías } \\
\text { análogas } \\
\text { (Instituto Geográfico } \\
\text { Militar Catastral) }\end{array}$} & 45 & 004 a la 009,037 a la 039,043 a la 048 & $1: 24.000$ & 1936 \\
\hline & A-47 & 076 a la 082 & 1:15.000 & 1939 \\
\hline & A-148 & 007 a la 010 & $1: 25.000$ & \multirow[b]{2}{*}{1940} \\
\hline & C-43 & 065 a la 067,098 a la 104 & $1: 22.000$ & \\
\hline \multicolumn{3}{|c|}{ Carta preliminar de Chía (Instituto Geográfico Militar Catastral) } & 1:25.000 & 1943 \\
\hline Mapa geológico (Ing€ & רas) & \multirow[b]{2}{*}{ 227-II-B, 227-II-D, 228-I-A y 228-I-C } & $1: 25.000$ & 2005 \\
\hline \multirow{2}{*}{\multicolumn{2}{|c|}{$\begin{array}{l}\text { Base cartográfica digital integrada } \\
\text { (Instituto Geográfico Agustín } \\
\text { Codazzi IGAC) }\end{array}$}} & & $1: 25.000$ & \multirow{2}{*}{2009} \\
\hline & & 227 y 228 & $1: 100.000$ & \\
\hline \multicolumn{3}{|c|}{ Ortofotomosaico digital (Instituto Geográfico Agustín Codazzi IGAC) } & \multirow{3}{*}{$\begin{array}{l}\text { ajustados a } 5 \\
\text { metros de } \\
\text { resolución } \\
\text { espacial }\end{array}$} & 2010 \\
\hline \multicolumn{3}{|c|}{$\begin{array}{l}\text { Modelo digital de elevación del terreno } \\
\text { (Instituto Geográfico Agustín Codazzi IGAC) }\end{array}$} & & 2014 \\
\hline \multicolumn{3}{|c|}{ Imagen de satélite (portal Google Earth) } & & 2019 \\
\hline
\end{tabular}

Fuente: elaboración propia.

Con base en las nuevas técnicas y herramientas de mapeo geomorfológico (Dramis, Guida y Cestari, 2011), se adecuó una base de datos SIG en la plataforma QGIS, la cual permitió el procesamiento y análisis de los datos y la información multiescala. La fotointerpretación geomorfológica se realizó en 3D y 2D a través de los softwares libres StereoPhoto Maker, Google Earth y QGIS. En el entorno SIG se efectuaron conjuntamente las operaciones de rectificación espacial de los insumos y la digitalización vectorial a escala 1:25.000, que recoge los elementos geomorfológicos interpretados (Figura 2). Se usó como apoyo un modelo digital de elevación del terreno (incluidos los modelos derivados de sombras y pendientes), cartografía topográfica y temática, y la imagen satelital del portal Google Earth ${ }^{T M}$.

Las aerofotografías antiguas dieron el mejor acercamiento para deducir y reconstruir las condiciones naturales. Las incertidumbres en la interpretación digital se solventaron mediante la fotointerpretación tradicional análoga con estereoscopios de espejos y bolsillo. La verificación y validación de la información fotointerpretada se realizó mediante recorridos y visita a sitios de inspección elegidos estratégicamente por su relevancia (febrero a julio de 2019); e incluyó el levantamiento de datos, muestreo de materiales, registro fotográfico y el dialogo con habitantes. Asimismo, se empleó la herramienta de uso libre GIS Cloud y su aplicación Mobile Data Collection, la cual facilitó el geoposicionamiento de los lugares de interés, el soporte cartográfico en terreno, la captura y almacenamiento virtual de datos, así como la incorporación de ajustes en la plataforma digital SIG y su posterior disposición en la nube. 


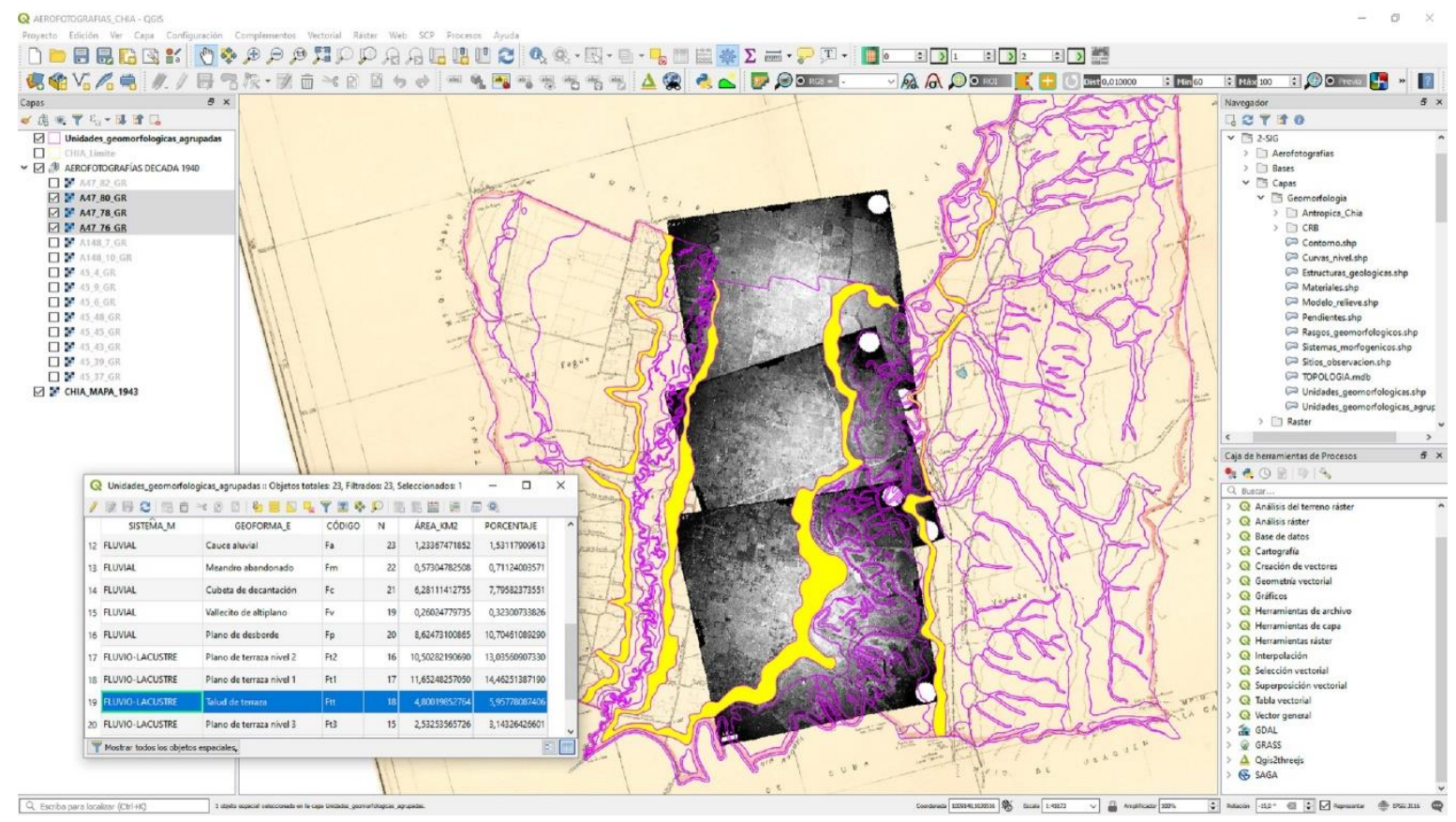

Figura 2: Interpretación y digitalización a partir de aerofotografías en el software QGIS Fuente: elaboración propia.

La clasificación geomorfológica definitiva consistió en la formulación tipológica final, lo cual implicó el agrupamiento de geoformas en función del modelo determinado por Flórez (2003), la CAR (2006) y el IDEAM (2010), con contribuciones del sistema desarrollado por el ITC (Van Zuidam, 1985; Verstappen y Van Zuidam, 1991; Carvajal, 2012; Zinck, 2012; Robertson et al., 2013; IGAC, 2018). El mapeo de unidades incorpora los aspectos y descripciones que se listan en la Tabla II, y se complementan con la identificación de componentes geomorfológicos lineales y puntuales (rasgos).

Tabla II: Atributos definidos para las geoformas naturales

\begin{tabular}{ll}
\hline Variable & Atributos \\
\hline Ambiente morfogénico & periglaciar heredado, estructural, coluvio-aluvial, fluvio-lacustre, fluvial. \\
\hline Geoforma especifica & frente, revés, cerro, vallecito, cono, talud, cubeta, meandro, cauce, etc. \\
\hline Tipo de pendiente & $\begin{array}{l}\text { plana, suave inclinada, inclinada, moderadamente escarpada, escarpada, } \\
\text { muy escarpada, extremadamente escarpada. }\end{array}$ \\
\hline Forma de la pendiente & recta, cóncava, convexa, irregular, compleja. \\
\hline Sustrato litológico & cuarzoarenitas, limolitas, arcillolitas. \\
\hline Formación superficial & residual, coluvial antiguo, coluvio-aluvial, aluvio-torrencial, lacustre, fluvial. \\
\hline Procesos dominantes & $\begin{array}{l}\text { tipo de remoción, tipo de erosión, tipo de inundación, disección, } \\
\text { compactación, etc. }\end{array}$ \\
\hline Área & -específica para cada caso- \\
\hline$\%$ de cubrimiento & -específico para cada caso- \\
\hline
\end{tabular}

Fuente: Basado en los trabajos: Van Zuidam (1985), Verstappen y Van Zuidam (1991), Flórez (2003), CAR (2006), IDEAM (2010), Carvajal (2012), Zinck (2012), Robertson et al. (2013) e IGAC (2018). 


\section{Resultados y discusión}

De acuerdo con las caracterizaciones geomorfológicas regionales realizadas por Vargas (2004); Carvajal (2004, 2005); CAR (2006, 2018) e IDEAM (2010), en la cuenca alta del río Bogotá se presentan relieves estructurales con influencia glaciar y periglaciar, una dinámica coluvio-aluvial importante proveniente de las vertientes montañosas, y destacadamente, modelados fluvio-lacustres y fluviales propios del Altiplano de Bogotá, también reconocido como de Altiplano cundiboyacense (Ceballos, 2007; Serrato, 2009) o "Sabana de Bogotá" (Rivera, 2004; Carvajal y Navas, 2016). Las singularidades morfogénicas (Figura 3), morfoevolutivas y de condicionantes regionales, conforman en conjunto los factores que, a través del tiempo, han determinado el desarrollo y la configuración geomorfológica natural actual del territorio municipal de Chía.

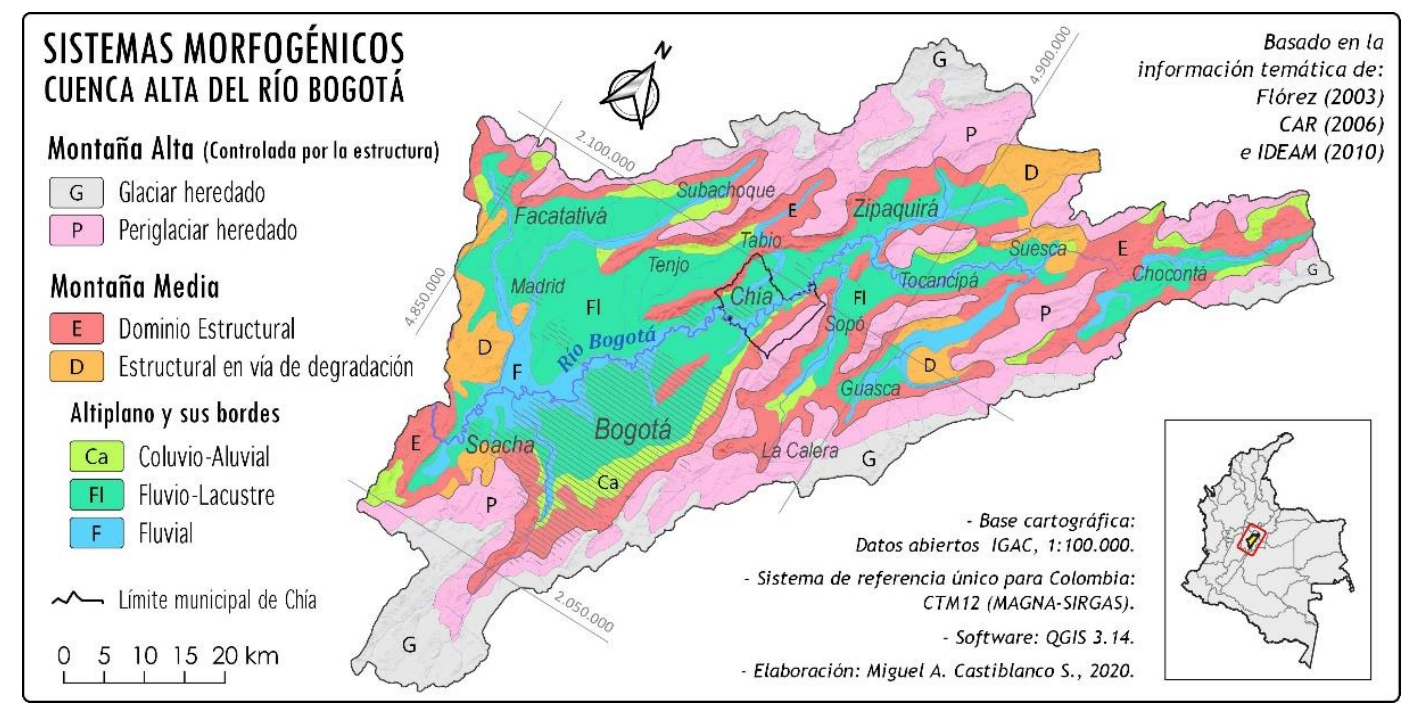

Figura 3: Contexto geomorfológico regional, cuenca alta del río Bogotá Fuente: basado en Flórez (2003), CAR (2006) e IDEAM (2010).

\subsection{Sustrato litológico y formaciones superficiales}

Según Helmens y Van der Hammen (1995) y Montoya y Reyes (2007), en Chía afloran las formaciones geológicas que se presentan en la Tabla III y en la Figura 4 (perfil transversal esquemático). Las rocas consolidadas son de tipo sedimentario del periodo Cretácico y se encuentran expuestas en diferentes grados a los procesos de plegamiento, fallamiento, fracturamiento y desgaste erosivo.

Las propiedades del sustrato rocoso determinan e influyen sobre las formas estructurales resultantes. El estilo muestra que las rocas consolidadas más antiguas son las más resistentes y se ubican en los bloques más elevados de los costados NE y SW del municipio; mientras que las formaciones menos resistentes y de edades más recientes, se sitúan hacia los bordes internos bajos en contacto con el altiplano. Otra característica destacable es la asociación existente entre el sustrato de alta resistencia y los relieves abruptos, y en oposición, la relación entre rocas blandas de baja resistencia y las morfologías suavizadas (CAR, 2006). 
Respecto a las formaciones superficiales, Montoya y Reyes (2007) identifican los depósitos que se describen en la Tabla III. Estas incluyen materiales residuales y no consolidados resultantes de la erosión, transporte y acumulación causada por los agentes externos (básicamente gravedad y agua).

La acumulación disímil en tipo y ubicación de las formaciones superficiales determina en parte el modelado de ciertas geoformas específicas: depósitos coluviales antiguos en forma de mantos sobre la alta montaña; depósitos coluvio-aluviales presentes en conos de derrubios, glacis y vallecitos; depósitos aluvio-torrenciales en forma de conos de deyección sobre el borde del altiplano (piedemonte); depósitos lacustres en el altiplano dispuestos en diferentes niveles de terrazas disectadas; y depósitos fluviales, propios de los valles que recorren la zona plana del municipio desde el NE en dirección SW.

Tabla III: Unidades crono-lito-estratigráficas

\begin{tabular}{|c|c|c|}
\hline Unidades & Edad & Características \\
\hline $\begin{array}{l}\text { Depósitos } \\
\text { fluviales }\end{array}$ & \multirow{4}{*}{$\begin{array}{l}\text { Holoceno } \\
\text { Pleistoceno } \\
\text { Superior }\end{array}$} & $\begin{array}{l}\text { Arcillas y limos presentes en los dos grandes valles aluviales (Bogotá y } \\
\text { Frío). Se reconoce geológicamente como la Formación Chía. }\end{array}$ \\
\hline $\begin{array}{l}\text { Depósitos } \\
\text { fluvio-lacustres }\end{array}$ & & $\begin{array}{l}\text { Acumulaciones antiguas y subrecientes de arcillas grises lacustres, con } \\
\text { capas de limos, arenas, gravas, turba, suelos enterrados y aportes de } \\
\text { ceniza volcánica. Se reconoce geológicamente como la Formación Sabana. }\end{array}$ \\
\hline $\begin{array}{l}\text { Depósitos } \\
\text { aluvio-torrenciales }\end{array}$ & & $\begin{array}{l}\text { Acumulaciones subrecientes de bloques y gravas, semi redondeados de } \\
\text { composición heterogénea, en matriz areno-limosa, generadas por el } \\
\text { transporte aluvio-torrencial. Se localizan en el piedemonte oriental. }\end{array}$ \\
\hline $\begin{array}{l}\text { Depósitos } \\
\text { coluvio-aluviales }\end{array}$ & & $\begin{array}{l}\text { Acumulaciones subrecientes y recientes de derrubios de origen hidro- } \\
\text { gravitatorio, bloques y clastos de forma angular y subangular, y tamaño } \\
\text { heterométrico. Se localizan sobre vallecitos y laderas bajas de la montaña. }\end{array}$ \\
\hline $\begin{array}{l}\text { Depósitos } \\
\text { coluviales } \\
\text { antiguos }\end{array}$ & Pleistoceno & $\begin{array}{l}\text { Acumulaciones antiguas de material heterogéneo, bloques y gravas en una } \\
\text { matriz arenosa, asociados en parte con la dinámica periglaciar } \\
\text { pleistocénica. Se localizan en la alta montaña oriental, depresión eje del } \\
\text { pliegue sinclinal. }\end{array}$ \\
\hline $\begin{array}{l}\text { Alteritas } \\
\text { residuales }\end{array}$ & $\begin{array}{l}\text { Neógeno } \\
\text { Superior }\end{array}$ & $\begin{array}{l}\text { Acumulaciones muy antiguas, desarrolladas por meteorización del sustrato } \\
\text { in situ en climas tropicales cálidos pre-levantamiento de la cordillera. Los } \\
\text { bloques, gravas y arenas se sobreponen a las Fms. Labor, Tierna y } \\
\text { Guaduas en la montaña oriental. }\end{array}$ \\
\hline Fm. Guaduas & $\begin{array}{l}\text { Cretácico } \\
\text { Superior }\end{array}$ & $\begin{array}{l}\text { Arcillolitas laminadas, coloridas, de consistencia blanda, moderadamente } \\
\text { fracturadas, en sectores altamente meteorizadas, con intercalación de } \\
\text { areniscas cuarzosas friables y resistencias regulares a pobres. Aflora en la } \\
\text { montaña oriental en las márgenes con el altiplano. }\end{array}$ \\
\hline $\begin{array}{l}\text { Fms. Labor } \\
\text { y Tierna }\end{array}$ & \multirow{2}{*}{$\begin{array}{l}\text { Cretácico } \\
\text { Superior }\end{array}$} & $\begin{array}{l}\text { Cuarzoarenitas de grano fino a grueso, poco cementadas, ligeramente } \\
\text { friables, de consistencia dura a moderadamente dura, en estratificación } \\
\text { gruesa con delgadas intercalaciones de arcillolitas y limolitas, } \\
\text { moderadamente a altamente meteorizadas, algo fracturadas y de } \\
\text { resistencia intermedia. Aflora en los flancos oriental y occidental. }\end{array}$ \\
\hline $\begin{array}{l}\text { Fm. } \\
\text { Plaeners }\end{array}$ & & $\begin{array}{l}\text { Limolitas, arcillolitas silíceas, liditas y areniscas de grano fino en } \\
\text { estratificación delgada a media, de consistencia dura a media, } \\
\text { moderadamente a débilmente meteorizadas, fracturadas y de resistencia } \\
\text { intermedia. Afloran al occidente, suroccidente, nororiente y suroriente. }\end{array}$ \\
\hline $\begin{array}{l}\text { Fm. } \\
\text { Arenisca } \\
\text { Dura }\end{array}$ & $\begin{array}{l}\text { Cretácico } \\
\text { Medio }\end{array}$ & $\begin{array}{l}\text { Cuarzoarenitas de grano fino a medio, bien cementadas, de consistencia } \\
\text { dura, estratificación gruesa, con intercalaciones de limolitas, arcillolitas y } \\
\text { liditas; débilmente a moderadamente meteorizadas; poco fracturadas y muy } \\
\text { resistentes. Afloran al nororiente. }\end{array}$ \\
\hline
\end{tabular}

Fuente: Adaptado de Helmens y Van der Hammen (1995) y Montoya y Reyes (2007). 


\subsection{Morfoestructura}

Según Van der Hammen (1995), la depresión tecto-sedimentaria subsidente que constituye el altiplano, es la mayor forma estructural para la cuenca alta del río Bogotá. En esta, las rocas consolidadas, plegadas, falladas, fracturadas y levantadas se encuentran parcialmente recubiertas por los depósitos fluvio-lacustres del Cuaternario (Khobzi y Usselmann, 1974).

De acuerdo con Flórez (1995), la orogénesis del Neógeno y el respectivo levantamiento de la cordillera permitió la conformación de nuevos relieves estructurales; un suceso que trajo consigo el incrementó del potencial hidrogravitatorio y erosivo, una activación en la disección del sustrato por las corrientes hídricas, así como el consecuente transporte de materiales hacia las depresiones.

Para la región, el plegamiento y fallamiento de las cadenas montañosas muestran una orientación general SW en dirección NE (Montoya y Reyes, 2007), lo que ha permitido como tendencia la conformación de vertientes con reveses estructurales amplios y frentes erosionales cortos (CAR, 2006). Adicionalmente, el control estructural afecta el sistema hidrográfico; los cauces principales se encuentran adaptados a la estructura general de los ejes sinclinales y anticlinales, mientras que las corrientes secundarias se asocian más al fallamiento y diaclasamiento local, con la disección transversal de pliegues, frentes erosionados y la formación de pequeñas gargantas (CAR, 2006).

En la parte central del municipio las condiciones morfoestructurales regionales han determinado la conformación de un amplio sinclinal, el cual se encuentra cubierto por los sedimentos derivados principalmente de la morfodinámica fluvio-lacustre (Figura 4). Los limites oriental y occidental del municipio corresponden a las divisorias de aguas de las subcuencas río Bogotá (sector Tibitoc-Soacha) y río Frío respectivamente.

Hacia el flanco oriental el plegamiento anticlinal supera los $3.200 \mathrm{~m} \mathrm{~s}$. n. m. en el sector Pan de Azúcar, expuesto en el pasado a la incidencia periglaciar. En el flanco occidental los pliegues se encuentran afectados por el fallamiento inverso de la Falla de El Porvenir (Montoya y Reyes, 2007), con un sistema secundario de tipo transcurrente sinistral; esta dinámica ha propiciado la elevación del sustrato rocoso a altitudes por encima de los $2.800 \mathrm{~m} \mathrm{~s}$. n. m.

\subsection{Aspectos morfoevolutivos y bioclimáticos: incidencia en la morfogénesis}

El área que ocupa actualmente la cuenca alta del río Bogotá y por ende el municipio de Chía, es resultado de una larga evolución geológica que se remonta 100 Millones de años atrás a inicios del Cretácico Superior (Sociedad Geográfica de Colombia, 1998; Van der Hammen, 1998; 2003). Según Montoya y Reyes (2007), la historia geológica comprende en principio el desarrollo de una gran cuenca sedimentaria, que durante los siguientes $80 \mathrm{Ma}$ transita entre transgresiones marinas, mares someros y ambientes costeros, los cuales determinan a su vez y continuadamente la acumulación de materiales. 
A comienzos del Mioceno Superior (entre 10 y $7 \mathrm{Ma}$ ), se intensifican los procesos orogénicos del que dan origen al levantamiento de la Cordillera Oriental colombiana (Flórez, 1995) (colisión compresiva entre las placas Sudamericana, Caribe y Nazca). Este ambiente continental, del cual posteriormente hará parte el Altiplano Cundiboyacense, experimenta el ascenso vertical de 600 a 2.600 m s. n. m. (Montoya y Reyes, 2007).

El primer escenario bioclimático significativo se gesta al final del Neógeno ( $3 \mathrm{Ma}$ aproximadamente). El sustrato rocoso se encuentra expuesto a las condiciones climáticas cálidas tropicales (Carvajal y Navas, 2016) y la alteración bioquímica resultante provoca la formación consecuente de alteritas, las cuales, en la actualidad, ocupan aún posiciones elevadas de la montaña (CAR, 2006). Los indicadores palinológicos muestran así un enfriamiento, que solo se puede explicar por un solevantamiento tectónico cercano de 2.000 metros de desnivel (Khobzi y Usselmann, 1974).

En los últimos $2 \mathrm{Ma}$, se definen los principales rasgos del relieve montañoso regional. Para la zona de estudio se manifiesta en el fallamiento del sustrato con plegamientos anticlinales estrechos y sinclinales amplios (Sociedad Geográfica de Colombia, 1998), pero de forma más relevante, con la formación de una gran depresión interna subsidente tipo sinclinorio, que permitió la constitución de una cuenca cerrada y el posterior represamiento de un gran lago (Van der Hammen, 1998). Este marco espacial recibió no solamente la acumulación de sedimentos lacustres y fluviales, sino, además, se enfrentó a los cambios climáticos que precisaron la morfodinámica glaciar y periglaciar en la constituida alta montaña (CAR, 2006).

Durante el periodo Cuaternario se gesta el segundo escenario bioclimático, ya que la Tierra en su conjunto se torna más fría y húmeda, la implicación regional fue la alternancia de varios ciclos glaciales e interglaciales, cuya última y máxima extensión se da entre 35.000 y 24.000 años AP (Van der Hammen, 1995). La dinámica bioclimática al final del Pleistoceno fijó la franja límite del sistema morfogénico periglaciar por encima del ecosistema de páramo de ese momento, es decir arriba de los $2.750 \mathrm{~m} \mathrm{~s}$. n. m. aproximadamente (CAR, 2006).

En los últimos 50.000 años el lago intramontano se drena debido a las variaciones pluviométricas y de humedad, como también por los procesos erosivos laterales y la inestabilidad regional asociada al tectonismo. La depresión se cubre gradualmente por los sedimentos lacustres con aportes importantes y puntuales de índole fluvial, glacial, coluvio-aluvial, de material orgánico (humus), y el aporte volcánico de cenizas procedentes de la Cordillera Central colombiana (Van der Hammen, 1998; 2003).

Para el caso de estudio, las implicaciones del clima nival fueron indirectas y el ambiente periglaciar no requirió necesariamente la presencia de masas glaciares, no obstante, las restricciones térmicas si permitían la gelifracción, impedían la colonización vegetal, y las frecuentes nevadas quedaban expuestas a la fusión y al escurrimiento hídrico que removió parte del material residual (CAR, 2006); este último 
proceso fue discreto para el territorio conocido hoy como Chía, razón por la cual son abundantes los depósitos residuales en la montaña oriental.

Finalizada la glaciación (12.500 AP aproximadamente), la alta montaña se transforma con el tercer escenario, que es el cambio climático holocénico, el nuevo estadio permite el ascenso del bosque altoandino en donde existía páramo (Van der Hammen, 1998), y la vegetación de páramo coloniza por su parte las zonas descubiertas con la respectiva formación de suelos orgánicos (CAR, 2006). De acuerdo con la CAR (2006, 2018), la última deglaciación (Tardiglacial) significó el aporte considerable de sedimentos desde las cuencas adyacentes hacia el conformado altiplano, con la intensificación de la depositación coluvio-aluvial y fluvio-torrencial a lo largo de la red de drenaje y en los bordes; así como la significativa colmatación fluvio-lacustre y la subsidencia respectiva de la "Sabana" (Carvajal y Navas, 2016).

Durante el Holoceno se da la configuración definitiva del actual Altiplano de Bogotá, con sus relieves montañosos circundantes (Rivera, 2004; Carvajal y Navas, 2016). Las morfologías depresionales y planas continúan recibiendo los aportes detríticos coluvio-aluviales laterales, con un incremento de la dinámica fluvial y la alineación de los valles aluviales de los ríos Bogotá y Frío. Estos valles se entallan sobre las formaciones lacustres dejándolas en una posición relativa más alta (CAR, 2006).

En el presente, el escenario bioclimático natural local se encuentra determinado por el predominio del bosque altoandino bajo un clima dominantemente de tipo frio seco; el desecamiento lacustre permitió la colonización de la cobertura vegetal terrestre a expensas de la acuática. En la montaña las áreas disectadas y los bordes inferiores del sistema periglaciar exponen una predisposición a los movimientos en masa, esta situación es favorecida por una mayor humedad dada por los frentes de condensación y las resurgencias de agua. En los valles aluviales bajos del altiplano es muy común la divagación fluvial condicionada por las suaves pendientes y la exuberancia hídrica de los periodos húmedos, con presencia de numerosos meandros abandonados, paleocauces, y relictos de humedales que desaparecen paulatinamente (CAR, 2006).

\subsection{Zonificación geomorfológica natural}

La clasificación geomorfológica natural representa los sistemas no perturbados por acciones antrópicas, y son el resultado de la morfoevolución regional y de las complejas relaciones dadas entre los condicionantes descritos anteriormente. La siguiente zonificación diferencia cinco ambientes morfogénicos y detalla en veintitrés unidades geomorfológicas específicas a escala 1:25.000 (Tabla IV y Figuras 4 y 5):

- Ambiente periglaciar heredado (controlado por la estructura)

Reconocido a nivel nacional como la montaña altoandina inestable. Presenta una connotación bioclimática debido a la influencia de los procesos crionivales del último periodo glacial, con la preservación de la morfología abrupta de origen estructural (Flórez, 2003; IDEAM, 2010). No manifiesta evidencias de formación glaciar, pero si se encuentra ligado a la fusión de las nevadas del pasado, con los limitantes térmicos hasta altitudes de $2.800 \mathrm{~m} \mathrm{~s}$. n. m. ( $\pm 100 \mathrm{~m})(\mathrm{CAR}, 2006)$. 
El periglacial heredado en el territorio municipal presenta control estructural y la red de drenaje está adaptada al plegamiento anticlinal y sinclinal. La disección de las corrientes hídricas de orden inferior es leve y son comunes los depósitos antiguos asociados a los cambios climáticos y la inestabilidad de las fuertes pendientes. Este ambiente es un frente actual de condensación que potencializa la acumulación de la humedad pluvial (Flórez, 2003; IDEAM, 2010); el periglaciar heredado se ubica en el costado montañoso oriental por encima de los 2.800 m s. n. m. ( $\pm 100 \mathrm{~m}$ ), con un cubrimiento espacial próximo a los $11 \mathrm{Km}^{2}$, que representa el $14 \%$ del total municipal.

\section{- Ambiente estructural}

Robertson et al. (2013) indican para este sistema una preponderancia de los procesos de levantamiento, plegamiento y fallamiento de las estructuras, donde las geoformas resultantes no se encuentran influenciadas o retocadas considerablemente por otros procesos morfodinámicos (como el periglaciar). Para este ambiente la distinción de los relieves se fundamenta en las diferencias litológicas, los contrastes de deformación del sustrato rocoso y las pendientes. En Chía, los relieves estructurales presentan morfologías escalonadas y alternadas por el tipo de sustrato (arcillolitas, limolitas, cuarzoarenitas). Las pendientes son dominantemente escarpadas, con un retroceso activo de las vertientes, una destacada concentración de la red de drenaje, mayor disección, y evidencias claras de movimientos en masa tipo derrumbes, desplomes y deslizamientos (IDEAM, 2010). En el municipio, el ambiente estructural se sitúa entre los $2.800 \mathrm{~m}$ s. $n$. m. que es límite inferior del periglacial $( \pm 100 \mathrm{~m})$ y la cota $2.580( \pm$ $20 \mathrm{~m}$ ) que es el contacto con los bordes del altiplano. El cubrimiento de este sistema alcanza los $16 \mathrm{Km}^{2}$, es decir, el $20 \%$ de la extensión municipal.

\section{- Ambiente coluvio-aluvial}

Incorpora las dinámicas geomorfológicas exógenas relacionadas con la transición y/o combinación de los procesos gravitatorios e hídricos; es decir los dados por la erosión, transporte y acumulación del material detrítico proveniente de los ambientes periglaciar heredado y estructural (CAR, 2006). Los modelados coluvio-aluviales incluyen de esta manera las geoformas asociadas a la red hidrográfica de la montaña, y que inciden sobre los bordes del altiplano concebido igualmente como un pequeño piedemonte. El ambiente coluvio-aluvial tiene un cubrimiento de $7 \mathrm{Km}^{2}$ (8\%).

\section{- Ambiente fluvio-lacustre}

Considera las geoformas resultantes de la dinámica lagunar del pasado pleistocénico. Las terrazas lacustres actuales derivan de los procesos de colmatación y desecamiento del gran lago que cubría la cuenca cerrada del alto Bogotá; cuya franja altitudinal se estableció alrededor de los 2.600 m s. n. m. ( \pm 20 m) (CAR, 2006), y cuya última fase en Chía se fechó en 40.000 años AP (Helmens y Van der Hammen, 1995). Este ambiente muestra una disección moderada y retoque fluvial de los ríos Bogotá, Frío y sus afluentes secundarios Santiamén, El Rincón, Honda y Tíquiza. El ambiente fluvio-lacustre y sus modelados son las geoformas más extensas en superficie para Chía con cerca de $29 \mathrm{Km}^{2}$, las cuales corresponden al 36 \% de la extensión municipal. 


\section{- Ambiente fluvial}

Comprende los terrenos dominados por la acción reciente de las corrientes de agua, donde operan activamente los procesos de erosión, transporte y acumulación aluvial en función de la pendiente, el caudal líquido y la carga sedimentaria (Robertson et al., 2013). Los diferentes procesos fluviales determinan la ocurrencia de crecientes temporales e inundaciones de tipo desborde (Flórez y Suavita, 1997; CAR, 2006). La dinámica fluvial de los ríos Bogotá y Frío ha modelado los dos valles representativos del territorio chiense, este sistema morfogénico es el de mayor dinámica para la zona de estudio, y cubre aproximadamente $17 \mathrm{Km}^{2}$, que representan el $22 \%$ de la jurisdicción municipal.

Tabla IV: Descripción de las geoformas especificas naturales

\begin{tabular}{|c|c|c|c|c|c|}
\hline \multicolumn{3}{|c|}{$\begin{array}{l}\text { Ambiente y } \\
\text { geoforma especifica }\end{array}$} & $\begin{array}{l}\text { Tipo y forma } \\
\text { de la pendiente }\end{array}$ & $\begin{array}{l}\text { Aspectos } \\
\text { morfodinámicos }\end{array}$ & $\begin{array}{l}\text { Referencia } \\
\text { geográfica actual }\end{array}$ \\
\hline \multirow{3}{*}{$\begin{array}{l}\text { I } \\
0 \\
0 \\
\frac{\pi}{0} \\
\frac{0}{0} \\
\frac{1}{1} \\
\frac{\pi}{0} \\
\frac{\pi}{0} \\
\frac{0}{0} \\
0\end{array}$} & Pfd & $\begin{array}{l}\text { Frente } \\
\text { erosional } \\
\text { en } \\
\text { sedimentitas } \\
\text { duras }\end{array}$ & $\begin{array}{l}\text { Escarpada a } \\
\text { extremadamente } \\
\text { escarpada. } \\
\text { Recta. }\end{array}$ & $\begin{array}{l}\text { Relieve montañoso, reconocido también } \\
\text { como ladera erosional de contrapendiente, } \\
\text { con desprendimientos, desplomes y } \\
\text { derrumbes, escurrimiento superficial } \\
\text { difuso, resurgencias de agua, deflación. }\end{array}$ & $\begin{array}{l}\text { Suroriente, en las } \\
\text { zonas montañosas } \\
\text { más elevadas de la } \\
\text { vereda Fusca. }\end{array}$ \\
\hline & Prd & $\begin{array}{l}\text { Revés } \\
\text { estructural en } \\
\text { sedimentitas } \\
\text { duras }\end{array}$ & $\begin{array}{l}\text { Escarpada. } \\
\text { Irregular } \\
\text { (plegada) }\end{array}$ & \multirow{2}{*}{$\begin{array}{l}\text { Relieves montañosos, reconocido también } \\
\text { como ladera estructural o de reverso, con } \\
\text { pequeños movimientos de tipo planar, } \\
\text { escurrimiento superficial difuso y } \\
\text { concentrado, reptación y solifluxión lenta y } \\
\text { superficial del suelo con graderías tipo } \\
\text { terracetas y pata de vaca, deflación, } \\
\text { disección incipiente, coluvionamiento en } \\
\text { los límites inferiores. }\end{array}$} & $\begin{array}{l}\text { Nororiente, sectores } \\
\text { montañosos más } \\
\text { altos de la vereda } \\
\text { Yerbabuena. }\end{array}$ \\
\hline & Prda & $\begin{array}{l}\text { Revés } \\
\text { estructural en } \\
\text { sedimentitas } \\
\text { duras con } \\
\text { alteritas }\end{array}$ & $\begin{array}{l}\text { Moderadamente } \\
\text { escarpada a } \\
\text { escarpada. } \\
\text { Irregular } \\
\text { (plegada). }\end{array}$ & & $\begin{array}{l}\text { De sur a norte por la } \\
\text { montaña oriental, } \\
\text { veredas Fusca y } \\
\text { Yerbabuena. }\end{array}$ \\
\hline \multirow{6}{*}{ 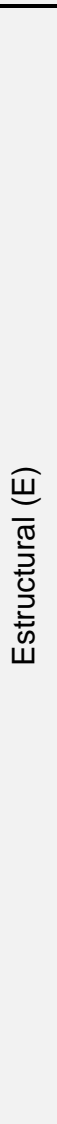 } & Efd & $\begin{array}{l}\text { Frente } \\
\text { erosional } \\
\text { en } \\
\text { sedimentitas } \\
\text { duras }\end{array}$ & \multirow{2}{*}{$\begin{array}{l}\text { Escarpada a } \\
\text { extremadamente } \\
\text { escarpada. } \\
\text { Irregular } \\
\text { (escalonada). }\end{array}$} & \multirow{2}{*}{$\begin{array}{l}\text { Relieves montañosos, con desplomes, } \\
\text { derrumbes y desprendimientos puntuales } \\
\text { y ocasionales de material meteorizado, } \\
\text { suelto e inestable. Escurrimiento } \\
\text { superficial difuso, incipiente desarrollo de } \\
\text { suelos, depositación de derrubios y } \\
\text { resurgencias de agua en zonas bajas. }\end{array}$} & $\begin{array}{l}\text { Pequeñas unidades } \\
\text { dispersas en la } \\
\text { montaña oriental y } \\
\text { occidental. }\end{array}$ \\
\hline & Efb & $\begin{array}{l}\text { Frente } \\
\text { erosional } \\
\text { en } \\
\text { sedimentitas } \\
\text { blandas }\end{array}$ & & & $\begin{array}{l}\text { Montaña oriental, } \\
\text { sector Castillo } \\
\text { Marroquín, El Espejo. }\end{array}$ \\
\hline & Erd & $\begin{array}{l}\text { Revés } \\
\text { estructural en } \\
\text { sedimentitas } \\
\text { duras }\end{array}$ & \multirow{3}{*}{$\begin{array}{l}\text { Moderadamente } \\
\text { escarpada a } \\
\text { extremadamente } \\
\text { escarpada. } \\
\text { Irregular } \\
\text { (plegada). }\end{array}$} & \multirow{3}{*}{$\begin{array}{l}\text { Relieves montañosos, con pequeños y } \\
\text { esporádicos deslizamientos de tipo planar } \\
\text { y rotacional especialmente en rocas } \\
\text { arcillosas. Ruptura y perdida del suelo, } \\
\text { reptación y solifluxión lenta, profunda, con } \\
\text { graderías tipo terracetas y pata de vaca } \\
\text { principalmente en rocas arcillosas. } \\
\text { Escurrimiento superficial difuso, } \\
\text { escorrentía intermitente concentrada, } \\
\text { desarrollo de coluviones y resurgencias de } \\
\text { agua en los limites inferiores. }\end{array}$} & $\begin{array}{l}\text { Cubrimiento extenso } \\
\text { a través de la } \\
\text { montaña occidental y } \\
\text { oriental. }\end{array}$ \\
\hline & Erda & $\begin{array}{l}\text { Revés } \\
\text { estructural en } \\
\text { sedimentitas } \\
\text { duras con } \\
\text { alteritas }\end{array}$ & & & $\begin{array}{l}\text { En la montaña } \\
\text { nororiental, vereda } \\
\text { Yerbabuena. }\end{array}$ \\
\hline & Erba & $\begin{array}{l}\text { Revés } \\
\text { estructural en } \\
\text { sedimentitas } \\
\text { blandas con } \\
\text { alteritas }\end{array}$ & & & $\begin{array}{l}\text { Montaña oriental, } \\
\text { sectores Castillo } \\
\text { Marroquín, Karina, La } \\
\text { Caro. }\end{array}$ \\
\hline & Ec & $\begin{array}{l}\text { Cerro } \\
\text { residual }\end{array}$ & $\begin{array}{l}\text { Moderadamente } \\
\text { escarpada a muy } \\
\text { escarpada. } \\
\text { Convexa. }\end{array}$ & $\begin{array}{l}\text { Relieves de degradación en forma de } \\
\text { loma o colina, con denudación por } \\
\text { meteorización y erosión intensa y } \\
\text { diferencial. Escorrentía superficial no } \\
\text { concentrada, remoción en masa y } \\
\text { acumulación de materiales al pie de } \\
\text { laderas. }\end{array}$ & $\begin{array}{l}\text { Pequeñas unidades } \\
\text { en las veredas } \\
\text { Fagua, Tíquiza, } \\
\text { Fonquetá, Cerca de } \\
\text { Piedra y al suroriente } \\
\text { en Fusca. }\end{array}$ \\
\hline
\end{tabular}




\begin{tabular}{|c|c|c|c|c|c|}
\hline \multirow{5}{*}{ 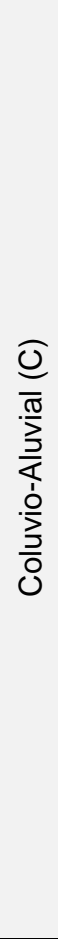 } & $\mathrm{Cl}$ & $\begin{array}{l}\text { Ladera } \\
\text { coluvial }\end{array}$ & $\begin{array}{l}\text { Inclinada a } \\
\text { moderadamente } \\
\text { escarpada. } \\
\text { Irregular. }\end{array}$ & $\begin{array}{l}\text { Modelado de acumulación, con } \\
\text { meteorización del subsuelo, } \\
\text { coluvionamiento, compactación, } \\
\text { ocasionalmente anegamientos, filtración } \\
\text { hídrica, deflación. }\end{array}$ & $\begin{array}{l}\text { Zonas elevadas de la } \\
\text { montaña oriental, } \\
\text { vereda Yerbabuena. }\end{array}$ \\
\hline & Cv & $\begin{array}{l}\text { Vallecito } \\
\text { de montaña }\end{array}$ & $\begin{array}{l}\text { Inclinada a } \\
\text { escarpada. } \\
\text { Compleja. }\end{array}$ & $\begin{array}{l}\text { Modelado de disección, con potencial } \\
\text { hidro-gravitatorio, acumulación detrítica, } \\
\text { dinámica torrencial con crecientes súbitas } \\
\text { ocasionales, remoción lateral tipo } \\
\text { pequeños derrumbes, meteorización del } \\
\text { subsuelo. }\end{array}$ & $\begin{array}{l}\text { Unidades distribuidas } \\
\text { en la montaña } \\
\text { oriental, veredas } \\
\text { Yerbabuena y Fusca. }\end{array}$ \\
\hline & $\mathrm{Cg}$ & $\begin{array}{l}\text { Glacis de } \\
\text { acumulación }\end{array}$ & $\begin{array}{l}\text { Ligeramente } \\
\text { inclinada a } \\
\text { moderadamente } \\
\text { escarpada. } \\
\text { Recta-cóncava. }\end{array}$ & $\begin{array}{l}\text { Modelados de acumulación en ladera, con } \\
\text { sedimentación de material fino y de poco } \\
\text { espesor. Erosión laminar del suelo, flujos } \\
\text { lentos y escurrimiento superficial difuso. }\end{array}$ & $\begin{array}{l}\text { Pequeñas unidades } \\
\text { situadas en zonas } \\
\text { bajas de la montaña } \\
\text { oriental y occidental. }\end{array}$ \\
\hline & $\mathrm{Cd}$ & $\begin{array}{l}\text { Cono de } \\
\text { derrubios }\end{array}$ & $\begin{array}{l}\text { Inclinada a } \\
\text { moderadamente } \\
\text { escarpada. } \\
\text { Irregular. }\end{array}$ & $\begin{array}{l}\text { Modelado de acumulación caótica, con } \\
\text { derrumbes, solifluxión lenta, reptación, } \\
\text { ondulaciones y rupturas del terreno, } \\
\text { escurrimiento superficial difuso y } \\
\text { concentrado. }\end{array}$ & $\begin{array}{l}\text { Suroccidente veredas } \\
\text { Fonquetá y Cerca de } \\
\text { Piedra; al oriente en } \\
\text { el sector Castillo } \\
\text { Marroquín. }\end{array}$ \\
\hline & Cy & $\begin{array}{l}\text { Cono de } \\
\text { deyección }\end{array}$ & $\begin{array}{l}\text { Ligeramente } \\
\text { inclinada a } \\
\text { inclinada. } \\
\text { Recta-convexa. }\end{array}$ & $\begin{array}{l}\text { Modelado de acumulación caótica, con } \\
\text { inestabilidad fluvio-torrencial en las } \\
\text { corrientes, compactación, disección } \\
\text { moderada, tunelización, hundimientos } \\
\text { menores, reptación superficial lenta y } \\
\text { resurgencias de agua. }\end{array}$ & $\begin{array}{l}\text { Transición montaña- } \\
\text { altiplano } \\
\text { (piedemonte), } \\
\text { veredas Yerbabuena } \\
\text { y Fusca. }\end{array}$ \\
\hline \multirow{4}{*}{ 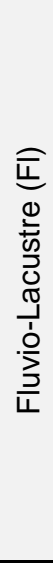 } & Flt3 & \multirow{3}{*}{$\begin{array}{l}\text { Plano } \\
\text { de } \\
\text { terraza }\end{array}$} & \multirow{3}{*}{$\begin{array}{l}\text { Plana. } \\
\text { Recta-irregular. }\end{array}$} & \multirow{4}{*}{$\begin{array}{l}\text { Modelados de acumulación dados en } \\
\text { ambiente lagunar, con compactación de } \\
\text { sedimentos, encharcamientos por lluvias, } \\
\text { niveles freáticos altos, desecamiento de } \\
\text { las pequeñas depresiones, disección } \\
\text { moderada, aportes detríticos en los bordes } \\
\text { de contacto con la montaña, retoque } \\
\text { sectorizado por el agente fluvial. En los } \\
\text { taludes retroceso de vertientes, disección } \\
\text { aluvial y pequeños carcavamientos. }\end{array}$} & $\begin{array}{l}\text { Al noroccidente } \\
\text { vereda Fagua, y al } \\
\text { oriente del altiplano } \\
\text { sector La Caro. }\end{array}$ \\
\hline & Flt2 & & & & $\begin{array}{l}\text { Ampliamente en los } \\
\text { bordes oriental y } \\
\text { occidental del } \\
\text { altiplano. }\end{array}$ \\
\hline & Flt1 & & & & $\begin{array}{l}\text { Todo el sector central } \\
\text { del altiplano, donde } \\
\text { se asienta la zona } \\
\text { urbana. }\end{array}$ \\
\hline & Fltt & $\begin{array}{l}\text { Talud } \\
\text { de terraza }\end{array}$ & $\begin{array}{l}\text { Ligeramente } \\
\text { inclinada. } \\
\text { Irregular. }\end{array}$ & & $\begin{array}{l}\text { Unidades alargadas } \\
\text { de norte a sur por } \\
\text { todo el altiplano en } \\
\text { Chía. }\end{array}$ \\
\hline \multirow{5}{*}{ 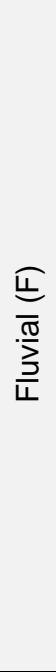 } & $\mathrm{Fv}$ & $\begin{array}{l}\text { Vallecito } \\
\text { de altiplano }\end{array}$ & $\begin{array}{l}\text { Plana a } \\
\text { ligeramente } \\
\text { inclinada. } \\
\text { Compleja. }\end{array}$ & $\begin{array}{l}\text { Modelado de disección, con crecientes } \\
\text { repentinas y esporádicas, encharcamiento } \\
\text { por lluvias, obturación, entallamiento } \\
\text { discreto por las quebradas. }\end{array}$ & $\begin{array}{l}\text { Al occidente en la } \\
\text { vereda Tíquiza, y al } \\
\text { oriente en los } \\
\text { sectores Caro y } \\
\text { Cuervo y La Caro. }\end{array}$ \\
\hline & $\mathrm{Fp}$ & $\begin{array}{l}\text { Plano de } \\
\text { desborde }\end{array}$ & $\begin{array}{l}\text { Plana. } \\
\text { Recta-cóncava. }\end{array}$ & $\begin{array}{l}\text { Modelado depresional, con desbordes por } \\
\text { crecientes periódicas, encharcamiento y } \\
\text { sedimentación. }\end{array}$ & \multirow{4}{*}{$\begin{array}{l}\text { Ocupación extensa } \\
\text { sobre el altiplano, de } \\
\text { norte a sur a lo largo } \\
\text { de los dos valles } \\
\text { aluviales: Bogotá y } \\
\text { Frío. } \\
\text { Estos modelados se } \\
\text { identifican en la } \\
\text { actualidad para varios } \\
\text { sectores bajos de } \\
\text { todas las veredas del } \\
\text { municipio, incluyen } \\
\text { zonas con dinámicas } \\
\text { complejas de } \\
\text { antropización. }\end{array}$} \\
\hline & $\mathrm{Fc}$ & $\begin{array}{l}\text { Cubeta de } \\
\text { decantación }\end{array}$ & $\begin{array}{l}\text { Plana. } \\
\text { Cóncava. }\end{array}$ & $\begin{array}{l}\text { Modelado depresional, con anegamiento } \\
\text { prolongado por desbordes periódicos, } \\
\text { colmatación, niveles freáticos altos. }\end{array}$ & \\
\hline & $\mathrm{Fm}$ & $\begin{array}{l}\text { Meandros y } \\
\text { cauces } \\
\text { abandonados }\end{array}$ & $\begin{array}{l}\text { Plana. } \\
\text { Compleja. }\end{array}$ & $\begin{array}{l}\text { Modelados arqueados y sinuosos, con } \\
\text { estancamiento de agua casi permanente, } \\
\text { acumulación y compactación constante de } \\
\text { sedimentos y material orgánico. }\end{array}$ & \\
\hline & $\mathrm{Fa}$ & $\begin{array}{l}\text { Cauce } \\
\text { Aluvial activo }\end{array}$ & $\begin{array}{l}\text { Plana. } \\
\text { Recta. }\end{array}$ & $\begin{array}{l}\text { Modelado cóncavo bordeado por vegas y } \\
\text { diques aluviales, con fluctuación hídrica } \\
\text { permanente, desbordes, erosión lateral, } \\
\text { socavación de bermas, avulsión y } \\
\text { divagación. }\end{array}$ & \\
\hline
\end{tabular}

Fuente: elaboración propia.

Nota: en Colombia la vereda es un tipo de subdivisión territorial de los municipios del país, que comprenden básicamente los espacios de tipo rural. 


\section{GEOMORFOLOGÍA NATURAL MUNICIPIO DE CHÍA}

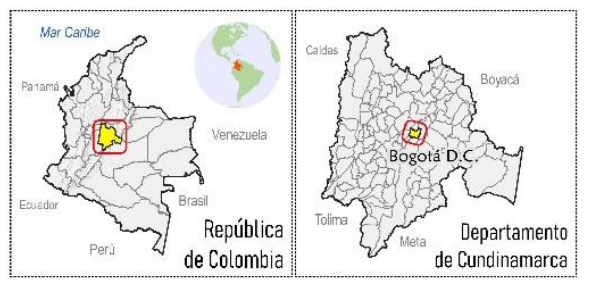

- Sistema de referencia único para Colombia: CTM12 (MAGNA-SIRGAS).

Base cartográfica:

Datos abiertos IGAC, 1:25.000.

- Software: QGIS 3.14.

- Elaboración:

Miguel A. Castiblanco S., 2020.

Nota:

Los limites

administrativos y la

toponimia corresponden

al estado actual del

territorio; los limites

pueden variar levemente

de los oficiales.

(1) $)^{>}$Sitio y dirección

de fotografía

en campo

(figura 6 del

documento)

COMPONENTES

GEOMORFOLÓGICOS

$\tau$ Pendiente estructural

- Falla de rumbo sinistral

...r. Falla inversa

Escarpe estructural

नrTh Escarpe erosional

$x$ Eje anticlinal

* Eje sinclinal

$\therefore$ Corriente hidrica

--c- Dique aluvial

Trmer Escarpe de terraza

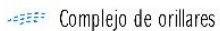

- Dirección flujo de cono

‘3000- Curva de nivel

\section{AMBIENTES MORFOGÉNICOS Y GEOFORMAS ESPEĆFIICAS}

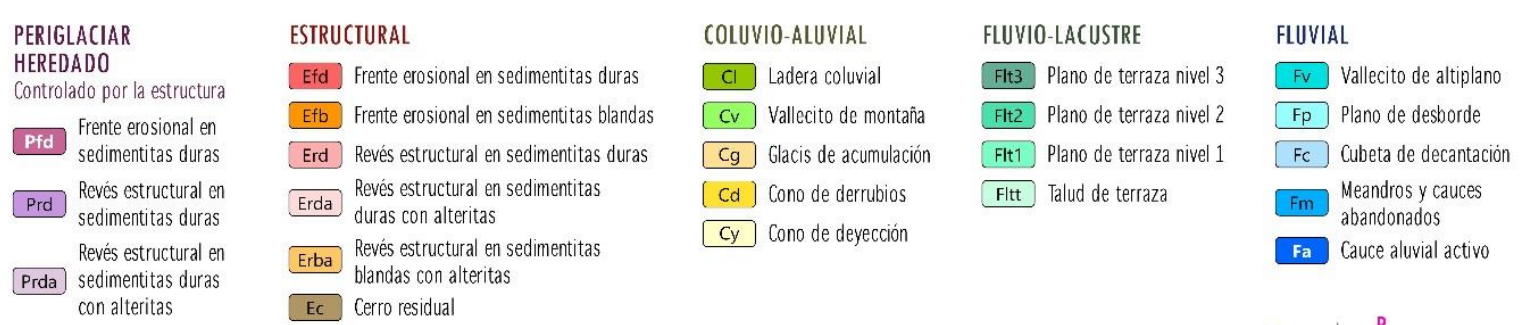

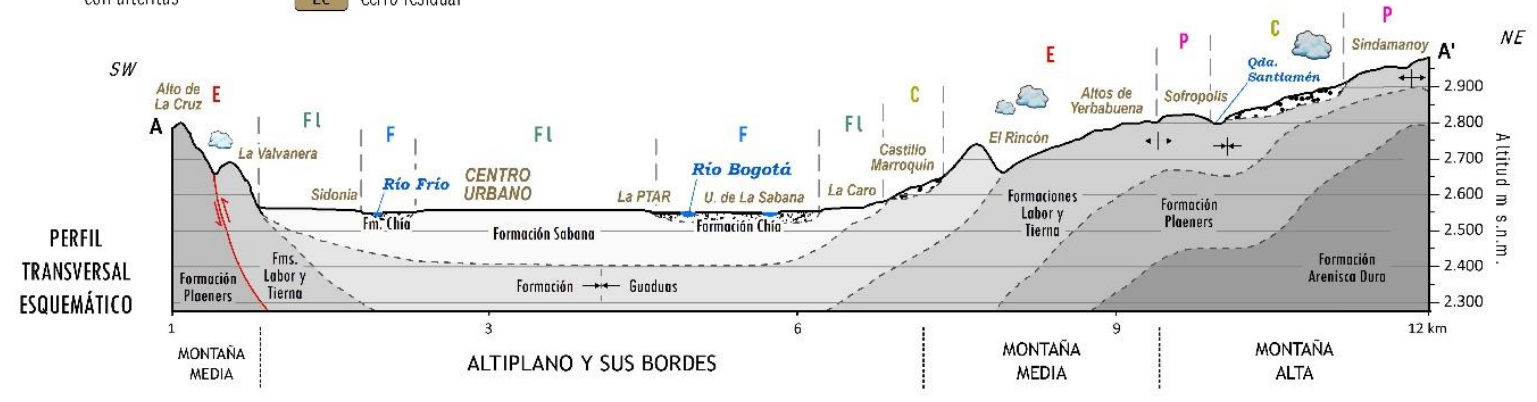

Figura 4: Geomorfología natural del municipio de Chía

Fuente: elaboración propia. 


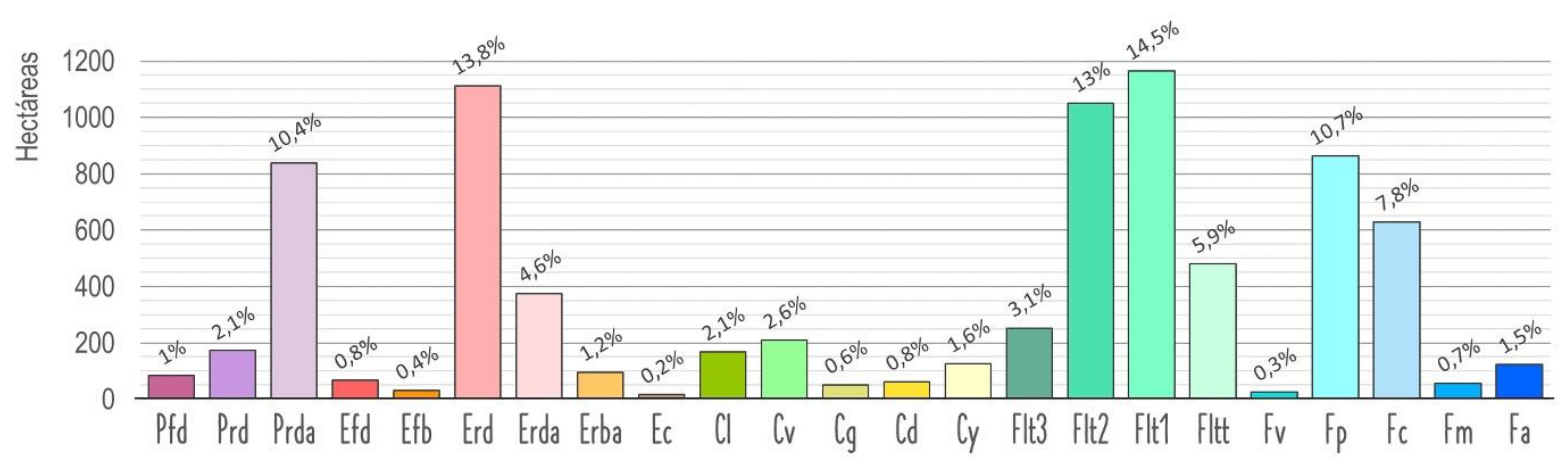

Figura 5: Cubrimiento espacial de las geoformas naturales específicas

Fuente: elaboración propia.

\subsection{Procesos morfodinámicos naturales actuales}

- Inestabilidad y potencial hidro-gravitatorio en la alta y media montaña

Las características del sustrato rocoso en Chía con rocas sedimentarias moderadamente resistentes a muy resistentes y medianamente meteorizadas, han dado una relativa estabilidad a las vertientes estructurales y con influencia periglaciar. No obstante, para los frentes erosionales (Pf y Ef) se evidencian desplomes y desprendimientos de baja incidencia, con volúmenes menores de material en las bases de estos relieves. En los reveses estructurales (Pr y Er) los deslizamientos son también fenómenos potenciales, pero poco frecuentes, los conos de derrubios $(\mathrm{Cd})$ identificados, son indicadores de la ocurrencia de este tipo remoción, con grandes volúmenes de material desplazado. Sobre los reveses son más comunes los derrumbes pequeños y puntuales.

De acuerdo con la CAR (2006), los movimientos en masa en la región se presentan especialmente debajo del límite inferior periglaciar, donde aumentan las pendientes, el material es suelto, la disección de las corrientes es profunda, el sustrato se encuentra más fracturado y meteorizado, y se evidencian huellas de erosión hídrica laminar difusa y concentrada. Los procesos de remoción lenta tipo solifluxión y reptación son en general comunes para las laderas montañosas del municipio, siendo más habituales en las geoformas constituidas por rocas arcillosas y materiales inestables en proceso de degradación (cerro residual Ec y ladera coluvial $\mathrm{Cl}$ ). Por su parte, en los vallecitos de montaña (Cv) son posibles los flujos hidro-gravitatorios torrenciales, debido al coluvionamiento y la escorrentía superficial que se concentra en los cauces. Como síntesis, las condiciones de inestabilidad natural para la montaña municipal se detonan e incrementan principalmente por el aumento de las lluvias estacionales y por la potencial actividad telúrica derivada de la sismicidad regional.

- Transferencia y amortiguamiento en el altiplano y sus bordes

En los bordes del altiplano se destaca en primer lugar la predisposición a flujos torrenciales tipo avenidas súbitas; los cuales descienden por los vallecitos de montaña e impactan básicamente los conos de deyección (Cy) y los vallecitos del altiplano (Fv); su acontecer esporádico depende de las lluvias inusuales y sucesos puntuales de remoción que aportan material a la red de drenaje. 
En los vallecitos del altiplano (Fv), que enlazan la red de drenaje de la montaña con los valles fluviales bajos Bogotá y Frío, se desarrollan procesos activos de sedimentación y las corrientes hídricas son poco funcionales (intermitentes y transitorias). Sin embargo, a pesar de la obturación natural de estos vallecitos con sedimentos y biomasa, el escurrimiento superficial concentrado sigue actuando ocasionalmente en función de los periodos de elevada humedad.

En el altiplano como tal, sobresale la disección superficial de la terraza fluvio-lacustre (Flt niveles 1, 2 y 3), dada por el sistema hidrográfico principal y en parte por las corrientes secundarias (Carvajal, 2005); como lo menciona la CAR (2006), este proceso fue significativo en el pasado, pero en los últimos tiempos se presenta de manera muy leve o es prácticamente inactivo. Sobre los niveles de la terraza fluviolacustre se presentan de manera habitual encharcamientos producto de las lluvias estacionales, las cuales se concentran en las pequeñas depresiones mal drenadas. En el ambiente fluvio-lacustre son igualmente comunes los procesos de compactación que generan hundimientos, ondulación, endurecimiento, agrietamiento de materiales y aumento del escurrimiento superficial; en los taludes de las terrazas, son frecuentes los procesos de coluvionamiento lateral y el flujo subsuperficial que alimenta los acuíferos y provoca de manera muy esporádica procesos de sufosión (piping).

En el ambiente fluvial de los valles de los ríos Bogotá y Frío, el proceso morfodinámico más representativo y predominante corresponde a las inundaciones generadas por las crecientes y desbordes lentos (CAR, 2006; 2018). Este tipo de inundaciones implican el aumento paulatino del nivel de las aguas, el transporte y acumulación de partículas finas, y sus efectos pueden durar desde varios días hasta algunos meses (Flórez y Suavita, 1997). Las crecientes lentas en los valles de Chía son detonadas por las fuertes precipitaciones que se dan en las cabeceras de las cuencas hidrográficas y pueden acompañarse por los flujos torrenciales laterales; los periodos húmedos en la región tienen un comportamiento anual bimodal, y se encuentran altamente influenciados por la ocurrencia de la anomalía climática ENOS en su fase conocida como Fenómeno de La Niña (CAR, 2018).

Los modelados y elementos geomorfológicos involucrados en la dinámica fluvial estacional de las inundaciones comprenden: el cauce aluvial activo (Fa), los planos de desborde (Fp), los meandros y cauces abandonados (Fm), los diques y orillares aluviales, y con mayor propensión las cubetas de decantación ( $\mathrm{Fc}$ ), las cuales albergan ecosistemas de humedales tipo chucuas (pantanos y lagunas).

Sumado a los desbordes de los ríos Bogotá y Frio, en los dos grandes valles del municipio se observan otros procesos morfodinámicos relacionados con el régimen fluvial natural, como son el aumento gradual en el nivel de base por la respectiva sedimentación aluvial, la erosión de los diques con socavación lateral, la consecutiva divagación (avulsión) de los canales con formación de orillares (barra de meandro), y la colmatación de los cuerpos de agua presentes en las cubetas; los cuales son entornos estratégicos de regulación ecosistémica y de amortiguación hidrogeomorfológica. 


\subsection{De lo natural a lo humano: primer panorama de la intervención antropogénica}

Con base en los resultados del marco geomorfológico natural, y a partir de una primera observación sobre las dinámicas de ocupación humana, se puede definir grosso modo y para concluir dos grandes escenarios a nivel municipal, los cuales han experimentado de manera diferencial la interacción societal:

A. La montaña: presente en los flancos oriental y occidental del municipio; de condición estructural, con retoque periglaciar heredado; morfologías elevadas y abruptas y el desarrollo dominante de procesos hidro-gravitatorios. La historia de ocupación antrópica para este escenario muestra en general un poblamiento incipiente, de tipo rural, con bajas densidades, que de manera preferente ha tendido a ubicarse sobre las laderas con menor pendiente y en las cimas de las estructuras a altitudes intermedias medianamente elevadas (<2.900 m s. n. m.). Las dinámicas geomorfológicas naturales que afrontan una mayor perturbación antropogénica son la erosión y la remoción puntualizada de materiales.

B. El altiplano y sus bordes: localizado en todo el sector central del municipio; dominado por los ambientes fluvio-lacustre, fluvial y coluvio-aluvial; con morfologías bajas, suaves y extensas; y la ocurrencia contrastada de procesos de inundaciones y sedimentación. Históricamente, el altiplano y sus bordes se convirtieron en los espacios de predilección para el asentamiento inicial de los pueblos prehispánicos (Flórez, 2003; Ceballos, 2007; Serrato, 2009), la posterior reterritorialización hispánica, y en las últimas décadas, para la conformación del complejo urbano con un desmedido crecimiento en población e infraestructura. Los procesos morfodinámicos que enfrentan una mayor perturbación antrópica son los desbordes periódicos, la sedimentación marginal y la divagación de los cauces.

En los últimos años, especialmente en los del siglo XXI, la antropización del medio biofísico se ha intensificado tanto en el contexto regional como para el marco local, con múltiples formas, tipologías, estados y grados de intervención. La urbanización se destaca como el motor principal de cambio, y el altiplano del municipio sobresale como el espacio geográfico con la mayor concentración de la huella antropogeomorfológica.

Las transformaciones y cambios más relevantes se identifican para los ambientes fluvial y fluvio-lacustre (Figura 6), donde el desarrollo de infraestructura urbana débilmente planificada ha derivado en la modificación de las geoformas naturales; así como en el aceleramiento de los diferentes procesos morfodinámicos. Los cortes, excavaciones, movimientos de material, aplanamientos, cambios en cursos, rellenos, y en general la indebida ocupación y modificación de los valles inundables (Bogotá y Frío), interfieren asimismo en el comportamiento de los desbordes y anegamientos, además de dificultar la estimación de sus posibles afectaciones. Otras prácticas como la deforestación sectorizada por actividades agropecuarias y residenciales, la explotación minera en canteras, adecuaciones hidráulicas en la red de drenaje secundaria, y la eliminación y relocalización del suelo y parte del subsuelo, inciden igualmente en desequilibrios respecto a los procesos de erosión y sedimentación. 
(1) Terraza fluvio-lacustre nivel 1 con crecimiento urbano y desarrollo vial.

Sector Fontanar, vereda Bojacá.

Al fondo reveses de la montaña nororiental con dinámicas de rururbanización. Vereda Yerbabuena.

(2) Cono de derrubios de la montaña suroccidental y terraza fluvio-lacustre nivel 2, con ocupación rural, suburbana y procesos de praderización. Sector Resguardo Indígena, vereda Cerca de Piedra.

(3) Talud de la terraza fluvio-lacustre y cubeta de decantación del río

Frío, afectadas por la deforestación y la disposición de escombros. Sector Sidonia, vereda Fonquetá.

(4) Talud de la terraza fluvio-lacustre y plano de desborde del río Bogotá, intervenidos por actividades agroindustriales, cortes, rellenos y aplanamientos para infraestructura vial. Sector Cuernavaca, vereda Fusca.

(5) Cubetas, cauce, diques y meandros abandonados del valle aluvial del río Bogotá,

antropizados por el sistema de transporte. Sector Universidad de La Sabana - Teletón.

Al fondo reveses de la montaña suroriental con canteras. Vereda Fusca.
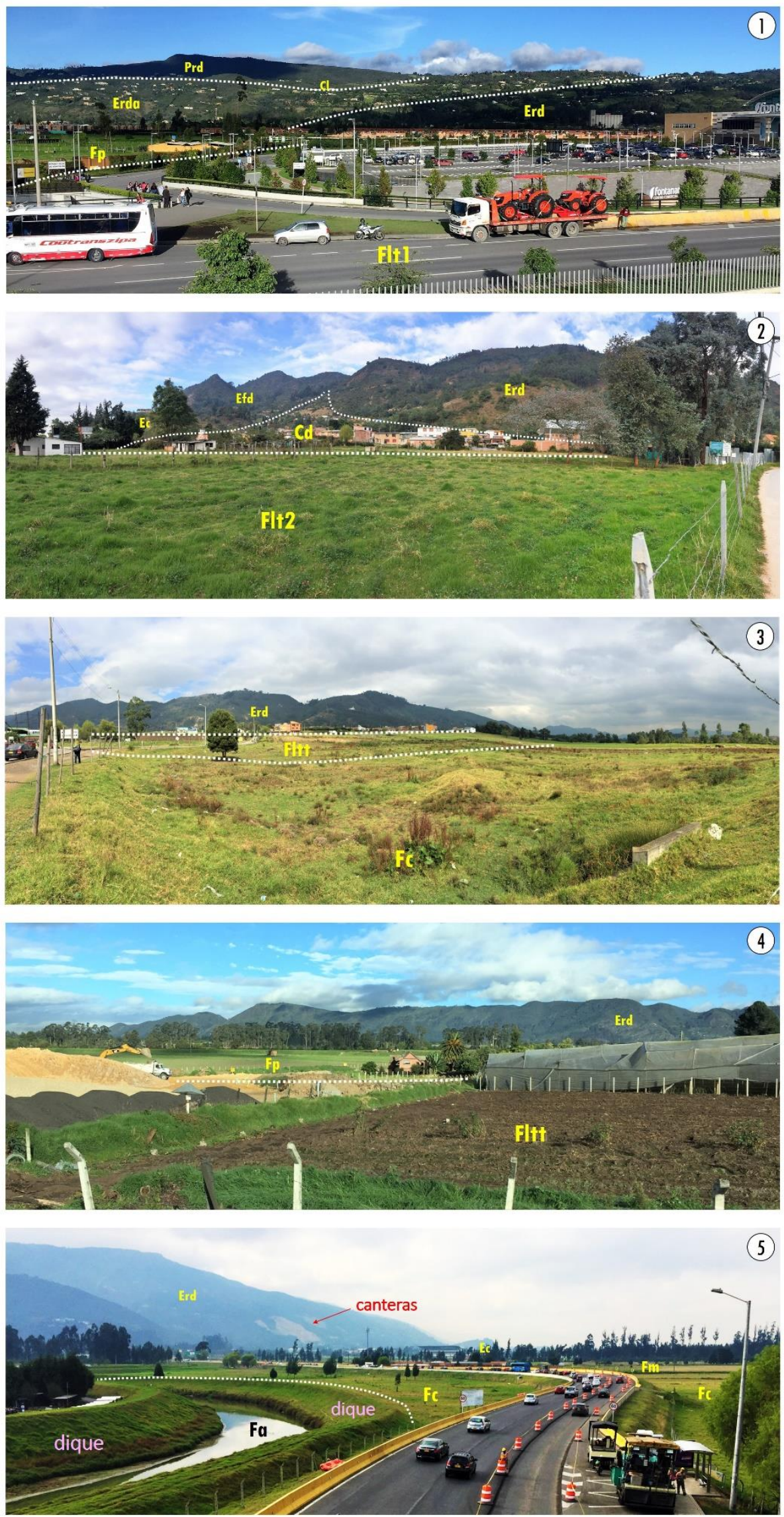

(5)

\section{.}




\section{Consideraciones finales}

La caracterización geomorfológica para el municipio de Chía ha permitido diferenciar, describir y explicar ambientes, relieves, modelados y sus procesos a escala semidetallada 1:25.000; con énfasis en los aspectos naturales y una aproximación a las condiciones originales o de pre-perturbación según los postulados de Nir (1983) y Rodrigues (2005). Para la zonificación fueron fundamentales los factores soportados teóricamente por el concepto "sistema morfogénico", el cual da preferencia al enfoque proceso-forma y a las condiciones de la morfodinámica; los aportes en materia cartográfica y de clasificación proporcionados por el Sistema ITC también contribuyeron significativamente en el levantamiento geomorfológico.

Los resultados responden a las preguntas planteadas sobre el tipo de geoformas naturales, su distribución y los procesos que operan en el municipio; el análisis de la morfoevolución y los factores condicionantes permitió detallar en las características de cinco ambientes morfogénicos con sus respectivas unidades específicas. En síntesis, se establecieron dos grandes escenarios: la montaña estructural y periglaciar situada en los flancos municipales y predispuesta a diferentes procesos hidrogravitatorios; y el altiplano fluvial y fluvio-lacustre con sus bordes coluvio-aluviales, ubicados en la parte central y sujetos de manera destacada a la sedimentación, compactación, encharcamientos por lluvias e inundaciones por desbordes.

En consecuencia, la caracterización elaborada cumple con el propósito de ser una base inicial, con información útil y pertinente; la cual no solo se concibe como un ejemplo metodológico para la caracterización geomorfológica municipal en Colombia, sino que, además, aporta conocimiento para afrontar nuevos estudios con énfasis en los análisis antropogeomorfológicos retrospectivos. Aunque el énfasis del presente artículo han sido las condiciones de orden natural, se consideró oportuno finalizar mediante esta primera aproximación del actuar humano; un panorama que evidencia detalles adicionales no contemplados, y que proyecta nuevas inquietudes respecto al papel e importancia de las acciones antrópicas en la construcción y/o deconstrucción del medio biofísico.

En conclusión, conforme lo plantea Szabó (2010), es necesario complementar este tipo de investigaciones y resultados a través del análisis más profundo del agente antrópico y con la misma importancia con la que se evalúan los otros factores, ya que el impacto geomórfico humano crece exponencialmente y su influencia trasciende los sistemas naturales. Continuar con el estudio de estas dinámicas relativamente recientes, de estos nuevos objetos espaciales, así como de sus características, patrones, tendencias e implicaciones, en relación con las dinámicas geomorfológicas naturales, proporcionará elementos favorables para la toma de decisiones territoriales. Para finalizar, se considera sustancial la consulta y aprovechamiento de los resultados por parte de quienes administran y planifican el territorio; estos productos y avances pueden apoyar y fortalecer las diversas tareas de gestión ambiental (incluyendo la del riesgo), más aún en un municipio donde el re-ordenamiento territorial presenta retos, controversias y requiere con premura adecuadas disposiciones. 


\section{Agradecimientos}

Al docente MSc. Héctor Jaime López Salgado por su valiosa orientación profesional, al Centro de Investigación y Desarrollo en Información Geográfica CIAF (IGAC) por el suministro de información e insumos. Se reconoce igualmente el apoyo académico dado por el Programa de Estudios de Posgrado en Geografía EPG, convenio interinstitucional Universidad Pedagógica y Tecnológica de Colombia UPTC - Instituto Geográfico Agustín Codazzi IGAC.

\section{Disponibilidad de datos}

El presente trabajo y sus resultados hacen parte de un proyecto de investigación posgradual; las capas de la zonificación geomorfológica natural local y sus atributos pueden ser consultados de manera pública en la dirección del portal QGIS Cloud: https://qgiscloud.com/macastiblancos/geomorfologia natural chia/

\section{Bibliografía}

CAR (Corporación Autónoma Regional de Cundinamarca). (2006). Plan de ordenación y manejo de la cuenca hidrográfica del río Bogotá: Elaboración del diagnóstico, prospectiva y formulación. Planeación Ecológica Ltda. - Ecoforest Ltda. Disponible en: https://www.car.gov.co/vercontenido/3692

CAR. (2018). Ajuste del plan de ordenación y manejo de la cuenca del río Bogotá. Fase de Diagnóstico. Volumen I - Caracterización Física; Volumen V - Gestión del Riesgo. Consorcio Huitaca. Bogotá. Disponible en: https://www.car.gov.co/vercontenido/94

Carvajal, J. H. (2004). Mapa geomorfológico de la Sabana de Bogotá. Versión 1.0. Escala 1:100.000. Ingeominas.

Carvajal, J. H. (2005). Características geomorfológicas de la Sabana de Bogotá. En: Proyecto compilación y levantamiento de la información geomecánica, zonificación geomorfológica de la Sabana de Bogotá, Vol. 1. Ingeominas, Bogotá. Disponible en: http://recordcenter.sgc.gov.co/B7/21003002502799/Documento/pdf/2105027991102000.pdf

Carvajal, J. H. (2012). Propuesta de estandarización de la cartografía geomorfológica en Colombia. SGC. Colección guías y manuales. Bogotá. Disponible en: https://www2.sgc.gov.co/Publicaciones/Cientificas/NoSeriadas/Documents/Propuesta\%20 de\%20estandarizacion.PDF

Carvajal, J. H. \& Navas, O. (2016). Bogotá “Savanna”. En: M. Hermelín (Ed.), Landscapes and Landforms of Colombia (pp. 115-126). London: Springer.

Ceballos, J. L. (2007). Patrones geomorfológicos de los asentamientos urbanos en Colombia. Perspectiva Geográfica, Revista del Programa de Estudios de Posgrado en Geografía, 12, 1-28.

Church, M. (2010). The trajectory of geomorphology. Progress in Physical Geography, 34 (3), 265-286. https://doi.org/10.1177/0309133310363992

Dramis, F., Guida, D. \& Cestari, A. (2011). Nature and aims of geomorphological mapping. En: M. J. Smith, P. Paron, \& J. Griffiths (Eds.), Geomorphological mapping: Methods and applications. Developments in Earth Surface Processes 15 (pp. 39-73). London: Elsevier. Disponible en: https://www.sciencedirect.com/science/article/pii/B9780444534460000033 
Flórez, A. (1995). Tecto-orogénesis, disección e inestabilidad de vertientes "en los Andes colombianos". Revista Ciencias Exactas Físicas y Naturales 19 (74), 527-534. Disponible en: https://raccefyn.co/index.php/raccefyn/issue/view/118/219

Flórez, A. \& Suavita, M. (1997). Génesis y manifestación de las inundaciones en Colombia. Cuadernos de Geografía - Universidad Nacional de Colombia, VI (1-2), 60-110. Disponible en: https://revistas.unal.edu.co/index.php/rcg/article/view/70792/64952

Flórez, A. (2003). Colombia: evolución de sus relieves y modelados. Universidad Nacional de Colombia. RET. Bogotá: Unibiblos. Disponible en: https://repositorio.unal.edu.co/handle/unal/53415

Goudie, A. S. \& Viles, H. A. (2016). Geomorphology in the Anthropocene. New York: Cambridge University Press.

Helmens, K. F. \& Van der Hammen, T. (1995). Memoria explicativa para los mapas del Neógeno-Cuaternario de la Sabana de Bogotá - Cuenca Alta del Río Bogotá. Análisis Geográficos 24 (pp. 91-142). IGAC. Bogotá. Disponible en: http://biblioteca.igac.gov.co/janium/Documentos/Analisis\%20Geogaficos\%2024.pdf

Huggett, R. J. (2017). Fundamentals of geomorphology (4th Ed.). Routledge.

IDEAM (Instituto de Hidrología, Meteorología y Estudios Ambientales). (2010). Sistemas morfogénicos del Territorio Colombiano. Bogotá. Disponible en: http://documentacion.ideam.gov.co/openbiblio/bvirtual/021769/021769.htm

IGAC (Instituto Geográfico Agustín Codazzi). (2018). Glosario de términos geomorfológicos aplicados a levantamientos de suelos. Grupo interno de trabajo de interpretación.

Khobzi, J. \& Usselmann, P. (1974). Problemas de geomorfología en Colombia. Bull. Inst. Fr. Et. And. III (4), 59-86.

Montoya, D. M. \& Reyes, G. A. (2007). Geología de la Sabana de Bogotá. Publicaciones Especiales del Ingeominas Vol. 28 (pp. 1-103). Bogotá.

Nir, D. (1983). Man, a geomorphological agent: an introduction to anthropic geomorphology. Jerusalem: Keter Publishing House.

Rivera, D. (2004). Altiplanos de Colombia. Libros de la Colección Ecológica del Banco de Occidente. Consultado el 20 de septiembre de 2019 en: https://www.imeditores.com/banocc/altiplanos/cap3.htm

Robertson, K. G., Jaramillo, O. \& Castiblanco, M. A. (2013). Guía metodológica para la elaboración de mapas geomorfológicos a escala 1:100.000. IDEAM. Bogotá. Disponible en: http://www.ideam.gov.co/documents/11769/152722/Guia Enero 201401+\%281\%29.pdf/50 1aa421-a0e4-4a1d-a5c8-d6cb1b0de520

Rodrigues, C. (2005). Morfologia original e morfologia antropogênica na definição de unidades espaciais de planejamento urbano: exemplo na Metrópole Paulista. Revista do Departamento de Geografia - USP (17), 101-111. Disponible en: http://www.revistas.usp.br/rdg/article/view/47278/51014

Serrato, P. K. (2009). Clasificación fisiográfica del terreno a partir de la inclusión de nuevos elementos conceptuales. Perspectiva Geográfica, Revista del Programa de Estudios de Posgrado en Geografía, 14, 181-218. Disponible en: https://revistas.uptc.edu.co/index.php/perspectiva/article/view/1722/1719 
Sociedad Geográfica de Colombia. (1998). Cuenca alta del río Bogotá; descripción y diagnóstico. Academia de Ciencias Geográficas. Santafé de Bogotá.

Szabó, J. (2010). Anthropogenic geomorphology: subject and system. En: J. Szabó, L. Dávid \& D. Lóczy (Eds.), Anthropogenic geomorphology: a guide to man-made landforms (pp. 310). London: Springer.

Van der Hammen, T. (1995). La última glaciación en Colombia (Glaciación Cocuy; Fuquense). Análisis Geográficos 24 (pp. 69-89). IGAC. Bogotá. Disponible en: http://biblioteca.igac.gov.co/janium/Documentos/Analisis\%20Geogaficos\%2024.pdf

Van der Hammen, T. (1998). Plan ambiental de la cuenca alta del río Bogotá. Análisis y orientaciones para el ordenamiento territorial. CAR. Santafé de Bogotá. Disponible en: http://sie.car.gov.co/bitstream/handle/20.500.11786/33796/28263.pdf?sequence=1\&isAllowed=y

Van der Hammen, T. (2003). La estratigrafía e historia del Neógeno y Cuaternario de la cuenca alta del río Bogotá: una evaluación después de completar el mapeo. Análisis Geográficos 26 (pp. 101-120). IGAC. Bogotá. Disponible en: http://biblioteca.igac.gov.co/janium/Documentos/Analisis\%20Geogaficos\%2026.pdf

Van Zuidam, R. A. (1985). Aerial photo-interpretation in terrain analysis and geomorphologic mapping. ITC. The Hague: Smits Publishers.

Vargas, G. (2004). Geomorfología. En: Aspectos geoambientales de la Sabana de Bogotá. Publicación especial No. 27. Ingeominas. Bogotá.

Verstappen, H. Th. \& Van Zuidam, R. A. (1991). El sistema ITC para levantamientos geomorfológicos (2th Ed.). ITC Publication 10. Enschede: Revised ed.

Zinck, J. A. (2012). Geopedología. Elementos de geomorfología para estudios de suelos y de riesgos naturales. Enschede: ITC Special Lecture Notes Series. Disponible en: https://webapps.itc.utwente.n//librarywww/papers 2012/general/zinck geopedologia 2012.pdf

Artigo recebido em/ Received on: 10/10/2020

Artigo aceite para publicação em/ Accepted for publication on: 12/12/2020 